\title{
Knowledge, Attitude, and Practice of Secondary School Students in Cairo Governorate towards injury prevention.
}

\author{
Maha M. Wahdan, Amany Mohamed Sayed, Khaled M. Abd El-Aziz, Moustafa \\ El-Houssini and Mohamed S. Al-Gwaily
}

Department of Community, Environmental and Occupational Medicine, Faculty of Medicine, Ain Shams University.

\begin{abstract}
Background: Injury is the leading cause of death and long term disability and a significant contributor to healthcare costs among children worldwide especially those aged 15 - 19 years. Objectives: To measure the prevalence of injuries among secondary school students in Cairo, Egypt, and to explore the knowledge, attitude and practice of students towards injuries and its prevention. Methodology: Cross-sectional study was conducted on secondary school students in eastern and western part of Cairo; a self-administered questionnaire was used for assessing sustained injuries in previous 12 months and the students' knowledge, attitude and practice towards injury and its prevention. Results: The overall prevalence of injuries among secondary school students was $68.5 \%$. There was a statistically significant difference between males and female, where knowledge score was higher in males and attitude score was found higher in females. But, there was no difference between them in practice score. Practice score was significantly lower among injured students than those not injured. Conclusion: The study showed high prevalence of injuries among adolescents. There is lack of awareness about injuries stressing the need for development of injury prevention program.
\end{abstract}

\section{Introduction}

Worldwide, injuries continue to be an important cause of morbidity, permanent disability and death over various age groups. Where injury is defined as "the physical damage that results when a human body is suddenly subjected to energy in amounts that exceed the threshold of physiological tolerance or the result of a lack of one or more vital elements, such as oxygen", 1,2

More than $95 \%$ of all injury deaths in children occur in low-income and middle-income countries. Unintentional injuries include road traffic crashes, drowning, burns, falls and poisoning. ${ }^{3}$

Road traffic injuries alone are the leading cause of death among 15-19year olds. Nonfatal road traffic injuries require hospitalization and may lead to disability which means high costs of treatment, rehabilitation, and lost productivity. $^{2}$

Adolescents are in the pre-driver age category, were over-represented in the number of traffic fatalities and injuries. As adolescents travel mostly by bicycle $(52 \%)$, on foot $(18 \%)$, by moped $(3 \%)$, are driven by a parent or 
a friend (17\%), or by means of public transport $(9 \%)$; that means most of them travel no protected way that is make adolescents particularly vulnerable in traffic. ${ }^{4}$

The etiology of youth injury involves a complex interplay between behavioral and environmental factors with the lack of knowledge, 'dangerous' notions, and too much confidence in one's own skills. These factors affect estimating the risk that a hazard may occur which is often underestimated among young adolescents. ${ }^{\mathbf{5 , 6 , 7}}$

Injuries are not inevitable; they can be prevented or controlled. So, providing the 'correct figures' or providing 'hard realistic' information would only be counter-productive. Behavior is constructed from behavioral intentions, attitude and knowledge. ${ }^{8}$

Consequently, safety education for youth could be an important factor in preventing road injuries as it has been shown that driver's and pedestrian's road safety knowledge, both, are poor and inadequate in low and middle income countries.

In Egypt, Injury represents $20 \%$ of total deaths. A total of $21.7 \%$ of nonfatal injuries occurred in age group $10-19$. In spite of that, limited attention has been paid to injuries as a major public health problem. The lack of attention is due to the deficiency of reliable and valid information about these types of injuries which hides the extent of the problem from policy makers. ${ }^{10,11}$

Little studies were conducted in Egypt to explore young Egyptians knowledge, attitude and practice towards injuries and another study on Road risk-perception and pedestrian injuries among students at Ain Shams University, Cairo, Egypt, which found that, there were inappropriate youths' road behaviors, which were significantly associated with pedestrian injury. ${ }^{9,12}$

So that, there is need to explore knowledge, attitude and practice of secondary school adolescents towards injury and its prevention for assessing the need of injury prevention program development.

\section{The Aim of the study:}

The aims of this work were to measure the prevalence of injuries (unintentional and intentional) among secondary school students, and to assess their knowledge, attitude and practice towards injuries and its prevention.

\section{Subjects and methods:}

\section{Study subjects}

Egyptian secondary school students aged 15-19 years of both sexes from different types of secondary schools in eastern and western part of Cairo.

\section{Study settings}

The study was conducted in different types of secondary schools (4 public, 4 industrial, 4 experimental and 1 private) in eastern and western part of Cairo.

Sampling technique: Multistage cluster sampling design was used to get a representative sample of students in these 2 areas. At the first stage, the sample was stratified according to school types (public, industrial, experimental and private) then schools were selected randomly from the list of schools obtained from the Ministry of Education. At the second stage, inside each school, school grades were stratified into $\left(1^{\text {st }}, 2^{\text {nd }}\right.$ and $\left.3^{\text {rd }}\right)$ then classes were randomly selected from 
each grade and all students in selected classes were eligible to participate.

\section{Sample size justification}

The sample size was calculated through calculating sample size for a cluster sample $=$ Simple Random Sample size $x$ Design effect. Where the design effect $=(1+(m-1)$ p) where $\mathrm{m}=$ size of the cluster and $\mathrm{p}=$ intracluster correlation coefficient. Assumed that the proportion to be evaluated $=0.21$ and a confidence interval of width $=0.2$, at $95 \%$ confidence interval. The sample size for Simple Random Sample $=72$. For correction for design (the cluster design) we had to estimate the ICC = .010 and the average cluster size (average number of respondent of each type in every cluster (type of school)). The average cluster size was 40 and ICC was 0.01 , we had a design effect of 1.39. So, the sample size of each group after correction was approximately 100 individual. By multiplication of 100 by 4 types of schools in each district, the whole sample was calculated as 800 students.

\section{Tools of the study}

Data were collected by anonymous self-administered questionnaire including questions for Demographic information, assessing student's sustained injuries in previous 12 months and questions for assessing students' knowledge, attitude and practice towards injury and its prevention. It was constructed and modified from questionnaire designed for protocol titled "Injury Survey for Secondary School Students in Egypt" by personal contact with Dr. Mostafa El-Hossini and epidemiological papers [Prevalence and Social Correlates of Injury among In-School adolescents in Botswana, and (The development of the Extended Adolescent Injury Checklist (E-AIC)]. ${ }^{\mathbf{1 4 , 2 5}}$

The questionnaire was translated into Arabic and tested by pilot study. Some modifications were done based on the feedback from students and colleagues.

Pilot study was conducted on convenient sample of students (30 students) of both sexes to ensure the clarity and to assess the comprehensiveness of the questionnaire.

\section{Data management and analysis}

The data was collected, coded and entered on Microsoft Excel Worksheet. Data was transferred to SPSS format (Statistical Package for Social Sciences version 20) for data checking, cleaning and lastly analysis of data. Descriptive analysis was done and the statistical test used was student $t$ test.

Knowledge score consisted of sum of scores of these variables: (the first cause of secondary school students deaths, can we prevent injuries, can we prevent road traffic related injuries, injuries are unpredictable and unavoidable, injuries occur without cause and its beyond me, Egyptian traffic law emphasize on using seat belt in front seat, Egyptian traffic law emphasize on using seat belt in back seat, Egyptian traffic law emphasize on not using mobile phones during driving, the least age for having driving license, Egyptian traffic law emphasize on using helmet for bicycles and motor cycles, and what is the advantage of wearing helmet). Where right answer took (2), don't know answer took (1), and wrong answer took (0). So, total score was 22.

Attitude score consisted of: (thinking that law must emphasize on application of seat belt laws, and thinking that law 
must emphasize on application of helmet use by motorcycles and bicycles drivers). Where attitude towards emphasizing on application of seat belt variable had: right answer took (2), don't know answer took (1), and wrong answer took (0). While attitude towards emphasizing on application of helmet use by motorcycles and bicycles drivers variable had: both type of cycles answer took (3), motorcycles only answer took (2), don't know answer took (1), and (no) answer took (0). So, total score was 5 .

Practice score consisted of: (wearing seat belt while in car, respecting traffic lights, and looking both sides before crossing streets). Where (no) answer took (0) or (yes) answer took (1). So, the total score was 3 .

\section{Ethical consideration}

The study was conducted after the approval of Ain Shams Ethical Committee, Ministry of Education and Educational administration, and Schools principals'. Oral ascents from students were taken and Confidentiality of information was maintained.

\section{Results}

A total of 897 secondary school students responded to study questionnaire $(52.4 \%$ female and $47.6 \%$ male). The overall prevalence of one or more injuries in the past 12 months was $68.5 \%$ [95\% confidence interval (CI): $65 \%$ - 71\%]. There was no significant difference between males and females in prevalence of injury.

It was found that $65.4 \%$ of students knew that injuries are preventable, $59.3 \%$ of them reported that cars accidents are preventable, and $67 \%$ of them thought that injuries occur without cause (Table 1).

Regarding their knowledge about road traffic injury prevention laws, $82.5 \%$ of students knew that the Egyptian law requires seat-belt use by passenger, $41.1 \%$ cited that the law requires helmet use by both motorcycle/ bicycle drivers, $82.9 \%$ knew that speaking on phone is prohibited by law, and $60.8 \%$ were don't know about the permitted age for driving license (Table 2).

Regarding their attitude and practice towards road traffic injury prevention, $79.2 \%$ of students thinking that it must be emphasized in the application of seat belt law. It was found that $55.5 \%$ of them wear seat-belt. $84.3 \%$ respect traffic lights and $96.5 \%$ look on both sides before crossing streets. Their attitude towards law application of helmet use was $62.5 \%$ agree, but, only $16.6 \%$ of those riding cycles wear helmet. The advantages of helmet use were known by $70.3 \%$ of students (Table 3).

It was reported that $49.6 \%$ of students had previous knowledge about injuries and its prevention and their knowledge was drawn mainly from family $(34.6 \%)$, life journey experience $(20.2 \%)$, mass media $(17.3 \%)$, and school $(8.3 \%)$.

There were statistical significant differences between gender and knowledge and attitude scores, where males were higher in knowledge score $(14.8 \pm 2.9)$ than females $(14.0 \pm 2.9)$. While females were higher in attitude score $(4.2 \pm 1.1)$ than males $(4.1 \pm$ 1.2). But, there was no difference between both males and females in practice score mean (Table 5).

On other hand, there was significant difference only in practice score mean in relation to injury occurrence, where 
injured students had lower practice score mean $(2.4 \pm .7)$ than those not injured $(2.5 \pm .8)$ (Table 6).

\section{Discussion}

Injuries were reported in $68.5 \%$ of participants in the previous 12 months. This prevalence rate was consistent to those found by study conducted in Michigan (68\%). But, it was higher than those found in Botswana (65.8\%), in Palestine (47.6\%) and in study conducted in Caribbean countries, where the prevalence was $54.3 \%$. On other hand, our study rates were lower than those found by study where selfreported injuries in past year among students in Southern Nigeria were $(93.8 \%){ }^{\mathbf{1 3 , 1 4 , 1 5 , 1 6 , 1 7}}$

There were no statistical significant difference between gender and occurrence of injury. This finding was similar to those found in studies conducted in Botswana, Palestine and Southern Nigeria. ${ }^{14,15,16}$

Regarding students' knowledge about road traffic injury prevention laws, $82.5 \%$ of students knew that the Egyptian law requires seat-belt use by passenger with similar finding was found in Armenia, where the awareness of the seat belt law was $76 \% .^{18}$

While, $41.1 \%$ cited that the law requires helmet use by both motorcycle/ bicycle drivers, $82.9 \%$ knew that speaking on phone is prohibited by law, and $60.8 \%$ were don't know about the permitted age for driving license.

Regarding students' attitude and practice towards road traffic injury prevention, $79.2 \%$ of students thinking that it must be emphasized in the application of seat belt law. This attitude rate was lower than that found in Malaysia, about $93.6 \%$ were convinced of seat belt importance and application. ${ }^{19}$

It was found that $55.5 \%$ of students wear seat-belt. Similar to $51 \%$ of respondents wore a seatbelt in Armenia and close to that stated by $60.3 \%$ of students in Iran. ${ }^{20}$

Looking on both sides before crossing streets reported by $96.5 \%$. Respect for traffic lights showed by $84.3 \%$ which considered lower than that found in Sao Paulo. ${ }^{21}$

Students' awareness about advantages of helmet use was cited by $70.3 \%$ of students. And their attitude towards law application of helmet use was showed by $62.5 \%$ of students. But, only $16.6 \%$ of those riding cycles wear helmet. And this rate of helmet use was closer to that found in India $(20.9 \%)$ and Iran $(22 \%)$. These lower rates may explained by the lack of enforcement which seems to have positively affected awareness of the law and in turn, the usage. But, the usage rate in Cambodia (60\%) was higher than reported in present study. $^{22,20,23}$

It was reported that $49.6 \%$ of students had previous knowledge about injuries and its prevention and their knowledge was drawn mainly from family $(34.6 \%)$, life journey experience $(20.2 \%)$, mass media $(17.3 \%)$, and school $(8.3 \%)$. while, in sao Paulo, most of participants took their knowledge from primary healthcare units (39.1\%), family (25\%), mass media $(18.4 \%)$ and at school $(17.4 \%)$. on the hand, in India, schools $(76 \%)$ played a major role in making students aware followed by family members $(9.69 \%)$, textbooks $(7.83 \%)$, mass media $(8.3 \%)$ while $(13.6 \%)$ students gave no response. ${ }^{\mathbf{2 2 4}}$ 
In order to assess and compare the levels of knowledge, attitude and practice between different groups of students, cumulative knowledge, attitude and practice scores were calculated. Statistical significant differences were found in knowledge and attitude scores between males and females, where knowledge score was higher in males. While attitude score was found higher in females. But, there was no difference between them in practice score mean.

On the other hand, there was significant difference only in practice score in relation to the probability of injury occurrence, where injured students had lower practice score mean than those not injured.

\section{Limitations of study:}

- As the questionnaire was selfcompleted, some participants may have misreported, either intentionally or inadvertently.

- Disapproval of Private school in west districts to participate.

- $3^{\text {rd }}$ grade were absent from all types of schools except in industrial schools.

\section{Recommendations:}

- There is a need to raise public awareness about the magnitude and burden of injuries among adolescents,

- Injury control and prevention programs should be done through combination of mass media and school-based interventions through establishing and applying an educational and training program targeted at injury prevention and control among school students as a part of the regular school educational curriculum.

\section{References}

1) Patton GC, Coffey C, Sawyer SM, Russell M Viner, Dagmar M Haller, Krishna Bose, Theo Vos, Jane Ferguson, Colin D Mathers (2009). Global patterns of mortality in young people: a systematic analysis of population health data. Lancet. 374(9693):881-92. 2.

2) Margie Peden, Kayode Oyegbite, Joan Ozanne-Smith, Adnan A Hyder, Christine Branche, AKM Fazlur Rahman, Frederick Rivara and Kidist Bartolomeos (2008). World report on child injury prevention. World Health Organization. Available at: http://whqlibdoc.who.int/publicatio ns/2008/9789241563574_eng.pdf? $\underline{\mathrm{ua}=1}$

3) Alison Harvey, Elizabeth Towner, Margie Peden, Hamid Soori and Kidist Bartolomeos (2009). Injury prevention and the attainment of child and adolescent health. Bulletin of the World Health Organization; 87:390-394. Available at: http://www.who.int/bulletin/volum es/87/5/08-059808/en/

4) F. Wegman, L. Aarts (Eds.) (2006). Cyclists and pedestrians. Advancing Sustainable Safety, SWOV Institute for Road Safety Research, Leidschendam, The Netherlands, pp 155-162. Cited in: Hans Feenstra, Robert A.C. Ruiter, and Gerjo Kok (2014). Evaluating traffic informers: Testing the behavioral and socialcognitive effects of an adolescent bicycle safety education program. Accident Analysis \& Prevention, vol. 73, 288-295.

5) Yogesh G. (2015). Pattern or injuries in fatal road traffic accidents: autopsy based study. Journal of evidence based medicine 
and healthcare, vol. 2, issue 4, 321-

327.

Available

at:

http://www.jebmh.com/latest-

articles.php?at_id=527

6) William Pickett, Holger Schmid, William F. Boyce, Kelly Simpson, Peter C. Scheidt, Joanna Mazur, Michal Molcho, Matthew A. King, Emmanuelle Godeau, Mary Overpeck, Anna Aszmann, Monika Szabo, and Yossi Harel (2002). Multiple Risk Behavior and Injury. Archives of Pediatrics and Adolescent Medicine, Vol. 156. Available at: http://hbsc.biu.ac.il/pdf/16.pdf

7) SWOV Institute for Road Safety Research. Fact sheet (2012). Risky traffic behavior among young adolescents. Available at: http://www.swov.nl/rapport/Factsh eets/UK/FS_young_adolescents.pd f

8) Reyna, V.F. and Farley, F. (2006). Risk and rationality in adolescent decision making: implications for theory, practice and public policy. In: Psychological science in the public interest, A Supplement to Psychological Science Vol. 7, No. 1, 1-44.

9) Jehan M. Ibrahim, Hannah Day, Jon Mark Hirshon, and Maged El-Setouhy (2012). Road risk-perception and pedestrian injuries among students at Ain Shams University, Cairo, Egypt. Journal of Injury and Violence Research, 4(2):65-72.

10) WHO (2010). Injury surveillance: a tool for decision-making. Annual injury surveillance report Egypt, 2009. World Health Organization. Available at: http://applications.emro.who.int/ds af/dsa1087.pdf
11) Seif El-din A. (2006). Surveillance system for road traffic accidents in Cairo Egypt. Faculty of Medicine, Cairo University, MD thesis in public health. Cited in: Jehan M. Ibrahim, Hannah Day, Jon Mark Hirshon, and Maged El-Setouhy (2012). Road risk-perception and pedestrian injuries among students at Ain Shams University, Cairo, Egypt. Journal of Injury and Violence Research, 4(2):65-72.

12) Hannah $R$ Day, Maged ElSetouhy, Mohamed El-Shinawi, Amr Assem. Mona Ismail, Maroa Salem, Gordon S Smith, and John Mark Hirshon (2010). Young Egyptians" perception, attitude and knowledge of injuries. Injury prevention, Vol. 16: 348351 Available

at: http://www.ncbi.nlm.nih.gov/pubm $\underline{\mathrm{ed} / 20587813}$

13) Rebecca M. Cunningham, Maureen A. Walton, Stephanie Roahen, Harrison, Stella M. Resko, Rachel Stanley, Marc Zimmerman, C. Raymond Bingham and Jean T. Shope (2011). Past Year Intentional and Unintentional injury Among Teens Treated In an Inner City Emergency Department. Journal of Emergency Medicine; 41(4): 418426. Available at: http://www.ncbi.nlm.nih.gov/pmc/ articles/PMC2892010/

14) Karl Peltzer (2009). Prevalence and Social Correlates of Injury Among In-School Adolescents in Botswana. African Safety Promotion: A Journal of Injury and Violence Prevention, Vol. 7, No1. 
15) Christine Jildeh, Ziad Abdeen, Haleama Al Sabbah, and Anastas Philalithis (2013). Unintentional Injuries among School-Aged Children in Palestine: Findings from the National Study of Palestinian Schoolchildren. International Journal of Population Research. Available at: http://dx.doi.org/10.1155/2013/629 $\underline{159}$

16) Jephtha C. Nmor, Kehi H. Nwaka, Kensuke Goto, Junko Toyosawa, Daisuke Fujita (2013). High rate of injuries among students in Southern Nigeria: An urgent call to action. Vol.5, No.12, 1965-1975. Available at: http://dx.doi.org/10.4236/health.20 $\underline{13.512266}$

17) Karl Peltzer (2014). Unintentional Injury and Social Correlates among In-School Adolescents in Seven Caribbean Countries. Mediterranean Journal of Social Sciences MCSER Publishing, Rome-Italy. Vol. 5, No. 20.

18) Sharon Anoush Chekijian, and Nune Truzyan (2012). Practices, Attitudes and Perceptions Toward Road Safety in Yerevan, Republic of Armenia. Annals of advances in automotive medicine; 56: 191200.

19) Redhwan AA and Karim AJ (2010). Knowledge, Attitude and Practice Towards Road Traffic Regulations Among University Students, Malaysia. The International Medical Journal Malaysia. Vol. 9, No. 2, 29 - 34.

20) Bakhshani N.M., Lashkaripour K., Bakhshani S., and Hossein BOR M. (2007). Prevalence of risk behaviors related to intentional and unintentional injuries among adolescents high school students of Sistan and Baluchistan, Southea of ST of Iran. Zahedan journal of research in medical sciences, Vol. 9, No. 3, 199 - 208.

21) Daniel Colicchio and Afonso Dinis Costa Passos (2010). Driving behavior among medical students. Revista da Associação Médica Brasileira. Vol. 56, No. 5.

22) C K Priyanka Raj, Shib Sekhar Datta, Jayanthi V, Zile Singh, and Senthilvel V (2011). Study of knowledge and behavioral patterns with regard to road safety among high school children in a rural community in Tamil Nadu, India. Indian journal of medical specialists. Vol. 2, No. 2, 110-113

23) Abdulgafoor M. Bachani, Casey Branching, Chariya Ear, Douglas R. Roehler, Erin $M$. Parker, Sotheary Tum, Michael F. Ballesteros and Adnan A. Hyder (2013). Trends in prevalence, knowledge, attitudes, and practices of helmet use in Cambodia: results from a two year study. Injury (International journal of the care of injured). Vol. 44, Suppl 4:S31-7.

24) Luiz Antonio Del Ciampo, Ivan Savioli Ferraz, Maria Tazima, Letícia Graziela Bachette, Karla Ishikawa, and Rodrigo Paixão (2012). Epidemiological and clinical characteristics of injuries among adolescents attended at an emergency service in the city of Ribeirão Preto, São Paulo. Sao Paulo Medical Journal. Vol. 130, No.1, 27-31. Available at: http://www.producao.usp.br/handle /BDPI/39882 
25) Chapman R, Buckley L, Sheehan M. (2011). Injuries across adolescence: an investigation using the extended adolescent injury checklist (E-AIC). Health Promotion Journal Australian, 22(2):128-33. 
Table (1): Distribution of students according to their general knowledge about injury:

\begin{tabular}{|l|c|c|}
\hline \multicolumn{1}{|c|}{ Variable } & No. & $\%$ \\
\hline Injuries are preventable & 587 & 65.4 \\
Yes & 139 & 15.5 \\
No & 171 & 19.1 \\
Don't know & 532 \\
\hline Cars accidents are preventable \\
\hline Yes & 210 & 59.3 \\
No & 155 & 23.4 \\
Don't know & 601 \\
\hline Injuries occur without cause and it was beyond me \\
\hline Yes & 149 & 67.0 \\
No & 147 & 16.6 \\
Don't know & 16.4 \\
\hline
\end{tabular}

Table (2): Distribution of students according to their knowledge about factors affecting RTI related injury prevention: $\quad \mathrm{N}=897$

\begin{tabular}{||l|c|c|}
\hline \multicolumn{1}{|c|}{ Variable } & No. & $\%$ \\
\hline \multicolumn{2}{|c|}{ The Egyptian traffic law requires seat belt for the passenger in front } \\
\hline Yes & 740 & 82.5 \\
No & 72 & 8.0 \\
Don't know & 85 & 9.5 \\
\hline \multicolumn{2}{|c|}{ The Egyptian traffic law requires helmet use by cycle's drivers } \\
\hline No & 110 & 12.3 \\
Motorcycles drivers only & 194 & 21.6 \\
Motorcycle / bicycle drivers & 369 & 41.1 \\
Don't know & 224 & 25.0 \\
\hline The Egyptian traffic law allows speaking on phone during driving \\
\hline Yes & 75 & 8.4 \\
No & 744 & 82.9 \\
Don't know & 78 & 8.7 \\
\hline The age limit for a driving license & 25.4 \\
\hline Right answer & 228 & 13.8 \\
Wrong answer & 124 & 60.8 \\
Don't know & 545 & \\
\hline
\end{tabular}


Table (3): Distribution of students according to their attitude and practice for RTA related injury prevention: $\quad \mathrm{N}=897$

\begin{tabular}{|c|c|c|}
\hline Variable & No. & $\%$ \\
\hline \multicolumn{3}{|c|}{\begin{tabular}{|l} 
Thinking that it must be emphasized in the application of seat belt law \\
\end{tabular}} \\
\hline Yes & 710 & 79.2 \\
\hline No & 26 & 2.9 \\
\hline Don't know & 161 & 17.9 \\
\hline \multicolumn{3}{|l|}{ Wearing seat belt } \\
\hline Yes & 532 & 55.5 \\
\hline No & 365 & 40.7 \\
\hline \multicolumn{3}{|l|}{ Respecting traffic lights } \\
\hline Yes & 756 & 84.3 \\
\hline No & 141 & 15.7 \\
\hline \multicolumn{3}{|c|}{ looking on both sides before crossing street } \\
\hline Yes & 863 & 96.3 \\
\hline No & 34 & 3.8 \\
\hline \multicolumn{3}{|c|}{ Thinking that it must be emphasized in the application of helmet use } \\
\hline No & 47 & 5.2 \\
\hline For motorcycles drivers only & 177 & 19.7 \\
\hline For motorcycle / bicycle & 561 & 62.5 \\
\hline drivers & 112 & 12.5 \\
\hline Don't know & & \\
\hline
\end{tabular}

Table (4): Distribution of students who ride cycles and their knowledge and practice about it:

\begin{tabular}{|c|c|c|}
\hline Variable & No. & $\%$ \\
\hline \multicolumn{3}{|l|}{$\begin{array}{l}\text { Riding cycle? } \\
\text { N }=897\end{array}$} \\
\hline No & 554 & 61.8 \\
\hline Yes & 343 & 38.2 \\
\hline \multicolumn{3}{|l|}{$\begin{array}{l}\text { Wearing helmet } \\
N=343\end{array}$} \\
\hline Always & 22 & 6.4 \\
\hline Sometime & 35 & 10.2 \\
\hline No & 286 & 83.4 \\
\hline \multicolumn{3}{|c|}{$\begin{array}{l}\text { The advantage from wearing helmet } \\
\mathrm{N}=897\end{array}$} \\
\hline Protection from air and dust & 17 & 1.9 \\
\hline Protection from sun rays & 8 & .9 \\
\hline Protection from head injury & 185 & 20.6 \\
\hline All & 631 & 70.3 \\
\hline None & 6 & .7 \\
\hline Don't know & 50 & 5.6 \\
\hline
\end{tabular}


Table (5): Distribution of knowledge, attitude and practice scores by gender:

\begin{tabular}{||l|c|c|c|c||}
\hline \multirow{2}{*}{ Variable } & \multicolumn{2}{|c|}{ Gender } & \multirow{2}{*}{ T test } & P \\
\cline { 2 - 3 } & $\begin{array}{c}\text { Male } \\
\mathbf{N}=\mathbf{4 2 7} \\
\text { (Mean } \pm \text { SD) }\end{array}$ & $\begin{array}{c}\text { Female } \\
\mathbf{N}=\mathbf{4 7 0} \\
(\text { Mean } \pm \text { SD) }\end{array}$ & & \\
\hline $\begin{array}{l}\text { Total KAP } \\
\text { score }\end{array}$ & $21.2 \pm 3.6$ & $20.7 \pm 3.6$ & 2.11 & $.035^{*}$ \\
\hline $\begin{array}{l}\text { Knowledge } \\
\text { score }\end{array}$ & $14.8 \pm 2.9$ & $14.0 \pm 2.9$ & 3.74 & $<.001^{*}$ \\
\hline $\begin{array}{l}\text { Attitude } \\
\text { score }\end{array}$ & $4.1 \pm 1.2$ & $4.2 \pm 1.1$ & 2.02 & $.044^{*}$ \\
\hline $\begin{array}{l}\text { Practice } \\
\text { score }\end{array}$ & $2.4 \pm .8$ & $2.4 \pm .7$ & 1.53 & .126 \\
\hline $\begin{array}{l}\text { Attitude, } \\
\text { practice } \\
\text { score }\end{array}$ & $6.4 \pm 1.5$ & $6.7 \pm 1.4$ & 2.35 & $.019 *$ \\
\hline
\end{tabular}

(*) variable is statistically significant at $(\mathrm{p}<0.05)$.

Table (7): Distribution of knowledge, attitude and practice scores by injury occurrence:

\begin{tabular}{|c|c|c|c|c||}
\hline \multirow{2}{*}{ Variable } & \multicolumn{2}{|c|}{ Injury occurrence } & \multirow{2}{*}{ T test } & P \\
\cline { 2 - 3 } & $\begin{array}{c}\text { No } \\
\mathbf{N}=\mathbf{4 2 7} \\
\text { Mean } \pm \text { SD) }\end{array}$ & $\begin{array}{c}\text { Yes } \\
\mathbf{N}=\mathbf{4 7 0} \\
(\mathbf{M e a n} \pm \mathbf{S D})\end{array}$ & .515 & .614 \\
\hline $\begin{array}{c}\text { Total KAP } \\
\text { score }\end{array}$ & $20.85 \pm 3.5$ & $20.98 \pm 3.6$ & 1.31 & .19 \\
\hline $\begin{array}{c}\text { Knowledge } \\
\text { score }\end{array}$ & $14.2 \pm 2.9$ & $14.5 \pm 2.9$ & .46 & .64 \\
\hline $\begin{array}{c}\text { Attitude } \\
\text { score }\end{array}$ & $4.2 \pm 1.1$ & $4.2 \pm 1.1$ & 2.08 & $.038^{*}$ \\
\hline $\begin{array}{c}\text { Practice } \\
\text { score }\end{array}$ & $\mathbf{2 . 5} \pm .8$ & $2.4 \pm .7$ & 1.42 & .155 \\
\hline $\begin{array}{c}\text { Attitude, } \\
\text { practice } \\
\text { score }\end{array}$ & $6.6 \pm 1.4$ & $6.5 \pm 1.5$ & .42 & \\
\hline
\end{tabular}

(*) Variable is statistically significant at $(\mathrm{p}<0.05)$. 